\title{
Brief flooding and counterconditioning as treatments for persisting avoidance*
}

\author{
ROBERTO PRADO-ALCALA \\ School of Medicine. National Liniversity of Mexico, .Mexico. D.F. \\ and \\ HAROLD BUSH, DOUGLAS STEELE, and LARRY REID \\ Bradley University. Peoria, Illinois 61606
}

\begin{abstract}
Rats, many of which were fixed with chronically indwelling electrodes for either positive or aversive intracranial stimulation (ICS), were trained to avoid footshock by climbing from a grid to a retractable ledge. After avoidance was established. footshock was terminated, rats were given a number of treatments, and were then tested for continuance of responding during extinction. Treatments involved testing the effects of brief response prevention (flooding) with or without application of ICS as a counterconditioner. Brief flooding with or without ICS was generally inefficient in reducing persistent responding, except when positive ICS was delivered in such a way that it shaped behavior incompatible with climbing to the ledge.
\end{abstract}

One procedure that facilitates extinction of avoidance is to force the $\mathrm{S}$ to remain in the formerly threatening place without opportunity to escape, a procedure labeled response prevention or flooding (Baum, 1970). When positive stimulation (an event when made contingent is a positive reinforcer) is programmed during response prevention, there is even more facilitation of extinction than with response prevention alone (Gordon \& Baum, 1971; Reid, 1973; Wilson \& Davison, 1971). Without implying any specific mechanism, the procedure of programming positive stimulation may be called counterconditioning.

In the avoidance paradigm described by Baum and with intense footshock, a 5-min response prevention period is not sufficient to reliably reduce responding compared to no treatment. When lateral hypothalamic intracranial stimulation (ICS) is used as a counterconditioner during $5-\mathrm{min}$ response prevention, responding to extinction is nil (Baum, Leclerc, \& St.-Laurent, 1973: Gordon \& Baum, 1971: Hunsicker, Nelson, \& Reid. 1973). It is of interest to determine parametrically, the limits within which counterconditioning of this type is successful, in order to provide a wider data base for deriving counterconditioning theory. This study. by programming positive ICS during only 2 or $1 \mathrm{~min}$ of response prevention, established that this brief treatment does not uniformly lead to attenuation of persisting avoidance. Also, it was shown that the delivery of ICS

*Supported. in part, by funds from Bradley University's Board for Research. which administers NSF Grant GU 3320. Psychologist Prado-Alcala's tenure at Bradley University was made possible by funds provided by Bradley University and National University of Mexico. This study is part of a research program codirected by Harold Miller. Counseling Center, Bradley. We thank Carol Dietzman for help with this work. Requests for reprints should be sent to L. Reid, Department of Psychology, Bradley University, Peoria, Ill. 61606. contingent upon behaviors incompatible to avoidance was more effective than noncontingent delivery of ICS.

\section{EXPERIMENT I}

\section{Method}

\section{Subjects}

All but a few of 32 adult male Sprague-Dawley rats were fixed with chronically indwelling electrodes. The electrodes were bipolar stainless steel and insulated except at the cross sections of the stimulating tips. Inspection of enlarged photographs of 50 -micron sections of the rats' brains indicated that electrode tips that yielded positive ICS were located 1.5 to $2.5 \mathrm{~mm}$ lateral to the midline, from 3.6 to $5.0 \mathrm{~mm}$ anterior to the interaural plane, and always below the medial lemniscus. The structure stimulated most was the medial forebrain bundle. There was no apparent correlation between exact site of positive ICS and its effectiveness as a counterconditioner. Sites that yielded aversive ICS were predominantly deeper and more lateral in the hypothalamus and may have stimulated the optic tract.

\section{Apparatus}

ICS was $60-\mathrm{Hz}$ sine waves of $0.25 \mathrm{sec}$ with intensities individually selected for each $\mathrm{S}$, but always less than 80 microA. Footshock was $1.6 \mathrm{~mA}$ and was generated by a Grason-Stadler shock source and scrambler. In order to prevent any interaction between the two kinds of stimulation, the ICS electrodes and the leads to the footshock source were never connected simultaneously.

Responsiveness to ICS was tested in a C-shaped alley. At one end was a startbox and at the other end a lever, the depression of which yielded ICS. Timers recorded the time it took the $S$ to move from the startbox until the first leverpress in the goalbox. and the time to take 27 ICSs.

The avoidance apparatus was modeled after one described in detail by Baum (1965). Briefly. it was a box with an electrifiable grid floor and a retractable ledge extending $7.0 \mathrm{~cm}$ through the width $(30.5 \mathrm{~cm})$ of one side of the square box, $15.2 \mathrm{~cm}$ above the floor. S's weight closed a switch in the ledge. 
Table 1

Treatment and Outcomes

Treatment

\begin{tabular}{|c|c|c|c|c|c|c|c|c|c|}
\hline \multirow{2}{*}{$\begin{array}{l}\text { Counter- } \\
\text { conditioner } \\
\text { Response Preven } \\
\text { tion Time (Min) }\end{array}$} & \multirow{2}{*}{$\begin{array}{l}\text { None } \\
0 \\
\end{array}$} & \multicolumn{2}{|c|}{ None } & \multicolumn{2}{|c|}{$-\mathrm{ICS}$} & \multicolumn{2}{|c|}{$\oplus \mathrm{ICS}$} & \multicolumn{2}{|c|}{$+\mathrm{ICS}$} \\
\hline & & 2 & 1 & 2 & 1 & 2 & 1 & 2 & 1 \\
\hline \multicolumn{10}{|c|}{ Trials to Extinction } \\
\hline Mean & 73.0 & 109.0 & 63.0 & 64.0 & 228.0 & 25.0 & 59.0 & 103.0 & 72.6 \\
\hline Median & 71.0 & 91.0 & 20.5 & 50.5 & 182.0 & 9.0 & 19.5 & 5.5 & 6.5 \\
\hline Range & 110.0 & 285.0 & 243.0 & 121.0 & 546.0 & 80.0 & 196.0 & 762.0 & 346.0 \\
\hline N & 6 & 6 & 6 & 4 & 4 & 4 & 4 & 12 & 12 \\
\hline
\end{tabular}

Note-+ICS refers to positive ICS, -ICS to aversive stimulation. $\oplus$ ICS refers to ICS to a positive site but at an intensity just below that which maintains pressing.

\section{Procedure}

Five to 7 days after surgery, Ss were placed in the goalbox of the alley and attempts were made to shape pressing for ICS. As this shaping proceeded, it became obvious that ICS for some Ss was aversive. These rats eventually received the aversive ICS to test its value as a "counterconditioner," once its aversiveness was verified. Twenty-seven ICSs were delivered to each S on a low platform in a circular open field of $.6 \mathrm{~m}$ in diam. $\mathrm{S}$ was then placed on the perimeter, and the time was measured until $S$ returned to the platform. Self-stimulating Ss returned almost immediately, Ss who received 0 ICS returned within 1 or $2 \mathrm{~min}$, and Ss whose ICS was judged to be aversive did not approach the place of ICS within at least $4 \mathrm{~min}$. Secondly, ICS elicited squealing, crouching, and backing away in all Ss judged to be stimulated aversively.

The 16 Ss that initially pressed for ICS were given further opportunity to press while ICS intensity was manipulated. From these tests two intensities were selected: (a) an intensity just below the lowest intensity that sustained pressing, and (b) an intensity that produced high steady rates of pressing without seizures or gross motor movements. Other Ss, some of which had electrodes, were placed in two control groups. All Ss were handled the same number of times regardless of whether or not they were being given ICS.

All Ss were then given the opportunity to run the length of the alley for the opportunity to press for 27 ICSs. Each test was two opportunities to run, with $30 \mathrm{sec}$ between opportunities. There were two tests a day for 3 days, with about $12 \mathrm{~h}$ between tests. As might be anticipated, Ss that received no ICS or ICS below reinforcing threshold did not evidence any systematic running to get to the lever. Ss with electrodes that yielded aversive ICS typically stayed in the startbox of the alley. Ss that pressed for ICS typically ran at least some trials to get ICS and always ran to get more ICS after they were "primed" (for a discussion of priming with ICS see Reid, Hunsicker, Kent, Lindsay, \& Gallistel, 1973).

Based on these tests, we were able to get a no-ICS group and three classes of ICS to use as counterconditioners: aversive ICS (no pressing or running for ICS and avoidance of place of ICS plus squeals with ICS), ICS below threshold for positiveness (pressing and running for ICS at about 50 microA, but little or no approach for ICS at less than 21 microA), and positive ICS (pressing at greater than 40 times a minute for ICS of greater than 40 micro A).

All Ss received identical avoidance training. Each $\mathrm{S}$ was placed in the avoidance chamber directly on the grid. After $10 \mathrm{sec}$, footshock came on and continued until the $S$ escaped to the ledge. Thirty seconds later, the ledge retracted, returning the rat to the grid; then the ledge moved back into the box to begin a new trial. $S$ avoided footshock by climbing to the ledge within $10 \mathrm{sec}$. If $\mathrm{S}$ left the ledge within $30 \mathrm{sec}$, the ledge retracted and returned, beginning a new trial.

Just after the 10th consecutive avoidance, footshock was terminated by disconnecting the leads to the shock generator. The $\mathrm{S}$ was then picked up and the shelf retracted. The Ss that received no response prevention were then placed in a pail next to the chamber for $2 \mathrm{~min}$. Ss that received response prevention were placed on the grid for $2 \mathrm{~min}$. Those Ss scheduled for response prevention and ICS had their electrodes connected and were returned to the grid for $2 \mathrm{~min}$ and received 54 trains of $0.25 \mathrm{sec}$ ICS with $2 \mathrm{sec}$ between ICS.

At the end of the $2 \mathrm{~min}$, all Ss were picked up, their electrode leads disconnected, and the rats placed upon the returned ledge. Thirty seconds after the $\mathrm{S}$ was put on the ledge, the ledge retracted and the same events were programmed as during training, except that no footshock occurred; however, the sounds of the shock scrambler continued as in training. Ss were allowed to continue responding until they met extinction criterion of 5 consecutive minutes on the grid.

Two days after the first test, the entire procedure was repeated for all Ss except those that received no response prevention. During this second test, however, only 1-min response prevention was given as treatment and only 27 ICSs were programmed for ICS groups.

Data taken before treatment included measures of responsiveness to ICS and measures of acquisition of avoidance: trials and avoidance to 10 for 10 avoidance, and seconds of shock taken on first trial. Measures of perseveration of responding following treatment were trials, and "avoidance" to extinction criterion and latency of first response after treatment.

\section{Results}

Summary of data of trials to extinction are presented in Table 1. The Kruskal-Wallis one-way analysis of variance was used to determine if the differences found among groups were reliable. The analyses indicated that there were no reliable differences among groups on the tests of treatment effectiveness on any of the separate measures of response strength.

An interesting feature of the data is the distribution of scores for the positive ICS group. Seven out of $12 \mathrm{Ss}$ of the positive ICS group made less than seven responses to extinction following their treatment, but the $S$ that responded most, 762 trials, was also of the positive ICS group. Evidently, the effects of programming periodic positive ICS during brief response prevention may range from a reduction of responding to seemingly no change 
Table 2

Treatment and Outcomes

\begin{tabular}{|c|c|c|c|c|c|c|c|c|}
\hline \multicolumn{9}{|c|}{ Treatment } \\
\hline $\begin{array}{l}\text { ICS } \\
\text { Delivery }\end{array}$ & \multicolumn{2}{|c|}{ Away } & \multicolumn{2}{|c|}{ Toward } & \multicolumn{2}{|c|}{ Periodic } & \multicolumn{2}{|c|}{ None } \\
\hline $\begin{array}{l}\text { Response Preven- } \\
\text { tion Time (Min) }\end{array}$ & 2 & 1 & 2 & 1 & 2 & 1 & 2 & 1 \\
\hline . & & & Trials & xtinctio & & & & \\
\hline $\begin{array}{l}\text { Mean } \\
\text { Median } \\
\text { Range }\end{array}$ & $\begin{array}{c}2.2 \\
0.0 \\
11\end{array}$ & $\begin{array}{l}48.6 \\
51.0 \\
71\end{array}$ & $\begin{array}{c}89.6 \\
35.0 \\
364\end{array}$ & $\begin{array}{c}212.3 \\
36.5 \\
672\end{array}$ & $\begin{array}{c}44.2 \\
48.0 \\
113\end{array}$ & $\begin{array}{l}118.4 \\
114.0 \\
304\end{array}$ & $\begin{array}{l}135.2 \\
144.0 \\
269\end{array}$ & $\begin{array}{l}169.8 \\
196.0 \\
229\end{array}$ \\
\hline
\end{tabular}

over what might be expected if no ICS were programmed, or occasionally to more responding.

There was no apparent relationship between running times and press rates for positive ICS and the effectiveness of positive ICS as a counterconditioner. The rat that made 762 responses to extinction, for example. was one of the best runners and pressers for ICS. Rats that had to be primed to run in the alley showed no pattern with regard to trials to extinction. Also, rats with just below threshold positive ICS took relatively few trials to extinction.

\section{EXPERIMENT II}

A second experiment was designed to test a hypothesis about the variability found among Ss that received positive ICS in Experiment I. It was postulated that this variability might be due to differential reinforcement of certain behaviors: i.e.. rats who received their ICS near the withdrawn ledge or while performing abortive escape responses might have extinguished slowly. while those Ss that received ICS when they were away from the withdrawn ledge extinguished quickly.

\section{Method}

\section{Subjects and A pparatus}

Twenty adult male Sprague-Dawley rats were implanted for positive ICS. Most electrodes were in or near the medial forebrain bundle of the lateral hypothalamus. Interestingly. three electrodes that supported relatively high rates of self-stimulation (from 26 to 50 presses a minute) had the tips in the entopeduncularis part of the internal capsule. The apparatus of Experiment I were used.

\section{Procedure}

The same basic procedures as in Experiment I were followed except that only positive ICS was given to $S$ s in several different ways. After preliminary tests. the 15 highest pressers for ICS were divided randomly into three experimental groups. The remaining five Ss were used as controls. All groups received the same avoidance and extinction procedures as described in Experiment I. but each of the groups received a different treatment during $2 \mathrm{~min}$ of response prevention. In one group. Ss received ICS for making movements toward the withdrawn ledge. or while jumping toward the box lid. In a second group. Ss received ICS for making movements away from the withdrawn ledge, while a third group received ICS every $2.25 \mathrm{sec}$ independently of movements they were performing. Control Ss received no ICS, only $2 \mathrm{~min}$ of response prevention. Total number of ICS given for the $2 \mathrm{~min}$ of response prevention equaled $57 \pm 1$. The whole procedure was repeated again for all groups about 2 weeks after the initial testing, but with $1 \mathrm{~min}$ of response prevention with rats receiving $27 \pm 1$ ICSs. Also, one S of the group that was to again receive ICS for responses toward the ledge became ill and therefore was not tested a second time, leaving the $\mathrm{N}$ for this group equal to four.

\section{Results}

Kruskal-Wallis one-way analysis of variance was performed on each of the pretreatment measures taken prior to the first treatment, with Ss' data grouped according to Ss' eventual treatment. These analyses indicated no reliable differences among groups prior to treatment (iargest $\mathrm{H}=3.7$. $\mathrm{p}$ about .30). The rank order correlation between trials to acquisition and trials to extinction equaled -.16 . These analyses allow analysis of posttreatment scores without taking into account pretreatment performance.

The three measures of posttreatment performance have a high degree of concordance: Kendall's coefficient of concordance (Kirk, 1968. p. 494) for measures after $2 \mathrm{~min}$ of treatment $=.87$ and after $1 \mathrm{~min}=.86$. Therefore. only the measures of trials to criterion are reported and discussed here.

Summary of the trials to criterion are presented in Table 2. Kruskal-Wallis analysis of variance indicated sufficiently reliable differences among groups $(\mathrm{H}=6.3$. $\mathrm{p}<.1>.05$ ) after $2 \mathrm{~min}$ of treatment to indicate further analysis of the differences. Mann-Whitney U tests between each of the groups receiving ICS and the group that received only response prevention indicated that only the group that received ICS for responses away from the ledge could be considered reliably different from the 2-min response prevention control $(\mathrm{U}=1 \cdot \mathrm{p}=$ .008: $U$ values for the other two comparisons were 9 and 6. $\mathrm{p}>$.1. for ICS away and ICS periodic, respectively). For multiple comparisons. Kirk (1968, p. 495) suggested using a procedure proposed by Ryan that sets the $p$ value for rejection of the null hypothesis at a value less than .009 for the two extreme comparisons. Consequently. we can conclude with confidence that providing ICS for movements away from the ledge 
reliably reduced responding.

A comparison between the trials to criterion of the group that received ICS for movements away from the ledge and the no-treatment control group of Experiment I leads to the conclusion that programming ICS for movements away from the ledge is more efficient in reducing responding that is no treatment ( $\mathrm{U}$ $=0, p=.002$ ). Comparison of the other two groups that received ICS with the no-treatment control group of Experiment I indicated that these two ICS treatment groups cannot be considered reliably different from no treatment ( $\mathrm{U}$ and $\mathrm{p}$ values in both comparisons were 9 and .165).

Time to climb to the ledge on the first trial of reacquisition of avoidance prior to the second set of procedures is another measure of the previous treatment, because this trial was the first trial after rats met extinction criterion in the previous test. The measure can be thought of as an index of the durability of the treatments. Although the differences among the groups are not great enough to meet standards of reliability, they are, nevertheless, interesting. The control group took a mean (M) of $11.5 \mathrm{sec}$ on the grid before they made it to the ledge, or a $\mathrm{M}$ of $1.5 \mathrm{sec}$ of shock. The group of ICS for movements away from the ledge took a $\mathrm{M}$ of 22.6 on the grid and $12.6 \mathrm{sec}$ of shock. The other two ICS groups took 14.1 and $18.5 \mathrm{sec}$ on grid, periodic ICS and ICS toward ledge, respectively. Kruskal-Wallis analysis yielded an $\mathrm{H}$ of $5.6, \mathrm{p}<.20$. The trials and avoidance prior to the second treatment were similar for all Ss; they typically met the standard in 11 trials, with only the first trial an escape response.

The analysis of trials to extinction criterion suggested no reliable differences among groups after $1 \mathrm{~min}$ of treatment $(\mathrm{H}=2.6, \mathrm{p}$ about .5$)$.

One other comparison is of interest. All rats of both Experiments I and II that received only response prevention $(\mathrm{N}=11)$ were compared with rats that received response prevention with positive ICS, regardless of the exact way ICS was delivered $(n=27$ or 26 for 2 - and $1-\mathrm{min}$ response prevention periods). These are comparisons between brief implosion or response prevention and counterconditioning. A Mann-Whitney U converted to $z$ for large samples (Kirk, 1968, p. 497) indicated that, with $2 \mathrm{~min}$ of treatment, the group receiving response prevention with ICS took fewer trials to extinction $(\mathrm{z}=2.2, \mathrm{p}=.01)$. The same procedure with the $1 \mathrm{~min}$ of treatment indicated no reliable differences between treatments $(z=.7, p=.2)$.

\section{DISCUSSION}

With the level of avoidance training in this and similar studies, response prevention alone is no more efficient than no treatment in reducing subsequent responding during extinction when the response prevention period is 5 min or less (Gordon \& Baum, 1971; Hunsicker et al, 1973; data presented here). When a periodic

counterconditioner is programmed during $5 \mathrm{~min}$ of response prevention, responding during extinction is reduced to nearly none (Gordon \& Baum, 1971; Hunsicker et al, 1973). At $2.5 \mathrm{~min}$ and $2 \mathrm{~min}$, there is some reduction in responding, but with such variability across Ss that it takes a large number of Ss for the mean effect to appear reliable (Hunsicker et al, 1973; data presented here). With 1 min of response prevention plus counterconditioning, there is no reliable effect of treatment. Obviously, the response prevention period can be lengthened to a point beyond which response prevention with or without counterconditioning will reduce subsequent responding to none. In this paradigm, this point is probably $10 \mathrm{~min}$ or more (Reid, Hunsicker, Sautter, \& Miller, 1972). The efficiency of counterconditioning is revealed, therefore, only at certain parameters of testing. When the treatment times are neither extremely long nor short and when there is a chance of a difference becoming apparent, response prevention with counterconditioning is a more effective treatment for reducing persisting avoidance than is response prevention alone.

Programming the counterconditioner to capitalize on its potential, not only to counter fear but to reinforce incompatible responses, was shown to be most effective. When the positive ICS was given for responses toward the ledge or for abortive avoidance responses, the result was an average increase in responses to extinction, but importantly variable results (see ranges in Table 2). Evidently, during brief response prevention periods, care must be taken to ensure proper management of the events, since a reputed treatment may actually exacerbate subsequent persisting avoidance in individual cases. This is particularly the case when treatment time is brief. Brief response prevention without counterconditioning has been shown (e.g., Reid, Taylor, \& Rassel, 1971; Rohrbaugh \& Riccio, 1970) to prolong extinction. This conclusion coupled with the conclusions drawn above leads to the strong suggestion that brief treatments should not be used if the goal is uniform reduction of persisting avoidance.

There have been some indications that brief aversive stimulation during response prevention will enhance or sensitize persisting avoidance (Reid et al, 1971). Although the enhancement with brief periodic aversive stimulation is not a strong effect, the data allow the conservative conclusion that sensitization is surely a possibility.

Brief response prevention, response prevention with aversive stimulation, brief response prevention with a counterconditioner reinforcing avoidance attempts, and brief response prevention with unsystematically applied counterconditioners may all be ineffective as treatments, or may actually lead to a "deterioration effect." Data from the animal laboratory lead to the prescription of prolonged response prevention with systematically applied counterconditioners to abate fear and to reinforce incompatible responses as the effective way to eliminate intractable avoidance. 


\section{REFERENCES}

Baum, M. An automated apparatus for avoidance training of rats. Psychological Reports, 1965,16, 1205-1211.

Baum, M. Extinction of avoidance responding through response prevention (flooding) in rats. Psychological Bulletin, 1970, 74, 276-284.

Baum, M., Leclerc, R., \& St.-Laurent, J. Rewarding vs aversive intracranial stimulation administered during flooding (response prevention) in rats. Psychological Reports, 1973, 32, $551-558$.

Gordon, A., \& Baum, MI. Increased efficacy of flooding (response prevention) in rats through positive intracranial stimulation. Journal of Comparative \& Physiological Psychology, 1971, 75, 68-72.

Hunsicker, J., Nelson, T., \& Reid, L. Two kinds of intracranial stimulation as counterconditioners of persisting avoidance in rats. Physiological Psychology, 1973, 1, 227-230.

Kirk, R. E. Experimental design: Procedures for the behavioral sciences. Belmont, California: Wadsworth, 1968.

Reid, L. D. Processes of fear reduction in systematic desensitization: An addendum to Wilson and Davison (1971).
Psychological Bulletin, 1973, 79, 107-109.

Reid, L. D., Hunsicker, J. P., Kent, E. W., Lindsay, J. L., \& Gallistel, C. R. The incidence and magnitude of the "priming effect" in self-stimulàting rats. Journal of Comparative \& Physiological Psychology, 1973, 82, 286-293.

Reid, L., Hunsicker, J., Sautter, F., \& Miller, H. Efficient deconditioning of avoidance: "II. Paper read at the Psychonomic Society meeting, St. I-ouis, Mo., November 2-4, 1972.

Reid, L. D., Taylor, C. L., \& Rassel, L. M. Efficient deconditioning of avoidance. Paper read at the Psychonomic Society meeting, St. Louis, Mo., November 11-13 1971.

Rohrbaugh, II., \& Riccio, D. C. Paradoxical enhancement of learned fear. Journal of Abnormal Psychology, 1970, 75. 210-216.

Wilson, E. T., \& Davison, G. C. Processes of fear reduction in systematic desensitization: Animal studies. Psychological Bulletin, 1971, 76, 1-14.

(Received for publication July 26, 1973; revision received October 15, 1973.) 